\title{
METHODOLOGICAL BASES OF ASSESSMENT OF THE LEVEL OF DEVELOPMENT OF THE WORLD BUSINESS ENVIRONMENT: GLOBAL AND REGIONAL VIEW
}

\author{
Olesia Finahina', Anna Pavlovska², Serhii Mylnichenko ${ }^{3}$
}

\begin{abstract}
An attempt to offer a methodology for analyzing the business environment as in a global context (of the world) as in regional level (of Ukraine), which would come from an empirical base provided by domestic world analytical organizations of the public and private sectors of the economy was made. Methodology. As part of the methodology of assessment of the level of development of the world business environment, the author conducted a preliminary analysis of twenty-five indices examined their constituents in order to avoid duplication of index components which would lead to a distortion of research results. As part of the regional methodology, an 8-stage algorithm was proposed for assessing the level of development of the business environment of the regions of Ukraine based on 40 selected and reasonable indicators that cover 7 main areas and reflect various aspects of the business environment. Results. Nine proposed indices that are in complex, its component composition, are not overlapping and complementary, so reflect and provide a quantitative description of each of the multiple facets of this phenomenon as the world business environment. An integral estimation of the business environment of Ukraine in a regional context has been carried out; an integral index of the level of development of the business environment of a region has been calculated; both of them can act as the objective quantitative criteria for the formation of regional clusters. Objective characteristics of the business climate of a certain territory (in our case, region or group of regions) are obtained. Practical implications. Following the proposed method, the analysis of the level of development of the business environment of 70 countries in the classification limits introduced by the author in previous studies (European, North American, Latin American, African, Far Eastern, Islamic, Indian, ocean), in order to further clustering and graphical interpretation of the results. The group of leaders is formed by countries that relate to different models of the business environment. The countries of the European model are Germany, Great Britain, Sweden, the Netherlands and Austria. North American model: Canada and the United States of America. Representative of the Far Eastern model is Japan, as well as Australia which belongs to other models. The group of outsiders include countries that have a poor integrated index of business environment development, they are representatives of the African (Angola, Congo, Chad), Islamic (Syria, Somalia, Sudan) and Island (Polynesia) models. The results of analyzing of the business environment of the regions of Ukraine show that in 2017 Lviv, Kyiv region became a cluster of high development. The index of development the business environment, calculated by us, proves the extremely expressed polarization and unevenness of the processes of development of territories. Value/originality. The results obtained with graphical and formulaic interpretation make it possible to understand the condition, problems, prospects of their overcoming, to outline directions of further development and opportunities to support the business environment in the regional and global context.
\end{abstract}

Key words: business environment, regional development, global development, methodology for analyzing the business environment, cluster.

JEL Classification: R11, R58, C02

\footnotetext{
Corresponding author:

${ }^{1}$ Cherkasy State Technological University, Ukraine.

E-mail: finaginaov@gmail.com

ORCID: http://orcid.org/0000-0002-7305-7441

${ }^{2}$ Cherkasy State Technological University, Ukraine.

E-mail: annasuray0@gmail.com

ORCID: https://orcid.org/0000-0002-7496-4035

${ }^{3}$ Cherkasy State Technological University, Ukraine.

E-mail: s.mylnichenko@chdtu.edu.ua
} 


\section{Introduction}

Despite of the globalization of the economy, international relations are still not a dominating character. Even in the Western European integrated economy national model business environment continues to play a decisive role. In connection with this question an explanation of how the style and culture of business, affecting the system, which operates at a different level, is required. Development of methods for analysis of the national business environment has not only theoretical but also highly practical value, and it is associated with the release characteristics of the business environment in different countries and create a complete picture of the business environment regions. Features and regularities of the functioning of the business improvement district in different countries are reflected in the works of such foreign scientists (Hayek, 1992; Lewis, 2007; Chukhno, 2008; Mazur, 2012; Ursula, 2012; Voronchak, 2013; Scarlett, 2014; Finigina, 2018; Pankova, 2019).

The purpose of the article is to develop a methodology for analyzing the level of development of the business environment of the world countries in a global and regional context and conducting an integrated assessment of the business environment. The results of the assessment will create conditions for regional and global comparison, will justify the results obtained, develop and implement a policy of both regional and state level, corresponding to the specific characteristics of each country, territory or region.

\section{The development index of the global business environment: methodological and theoretical aspects}

Statement of the main material of the study. To date, there are about 80 indices, which are calculated by international analytical organizations in the context of the world countries. Almost half of them are in one way or another connected with the functioning and development of the business environment of these countries.

We analyzed 25 indices, examined their components in order to avoid duplication of the components of the indices, leading to a distortion of the results of the research that we set to carry out. Among this grouping, 9 indices were selected that, in a complex, by their component composition, rather than duplicating each other, but complementing, thus reflecting and providing a certain quantitative characteristic of each facet of such a multivariate phenomenon as the business environment: Country Brand Index; Democracy Index; Index of Economic Freedom; Human Development Index; Press Freedom Index; Corruption Perceptions Index; Global City Competitiveness Index; Ease of Doing Business Index; Fragile Country Index.
We propose an algorithm for assessing the level of development of the business environment of the world countries which is based on 9 selected and wellgrounded world indices, which is graphically reflected in Figure 1.

The above methodologycan be used to assess thelevel of development of the business environment in the context of the regions. The main problem in this case may be the lack of some index characteristics in the regional context for Ukraine, therefore in the future research the author will propose an adapted methodology for assessing the level of development of the business environment of the regions of Ukraine, based on domestic statistics and expert assessments. The analysis uses the index method, the rating method, the cluster and graphical analysis. A complex multi-stage process consisting of 6 steps, which we will describe below.

A) Critical selection of indices, which in their complex, by their component composition, rather than duplicate each other, but complement, thus reflect and provide a certain quantitative characteristic of each facet of such a multivariate phenomenon as the business environment. B) Introduction of information one-pointedness of the selected indeces. All the indices selected by us, reflecting the different facets of the development and functioning of the business environment of the country in order to obtain informational one-pointedness, must be delineated into stimulants and destimulators, thus the link between the level of development of the business environment of the country and the stimulator will be direct, and, accordingly, with destimulators turns out to be inverse.

B.1) Stimulators are assigned a direct rating (from 1 to 70 , where 1 is a sign of a high level of this criterion for the development of the business environment).

B.2) Destimulators assign a reverse order rating (from 1 to 70 , where 1 is a sign of a high level of this criterion for the development of the business environ-ment).

B.3) We carry out the calls of the indices, where the stimulants are aimed at bringing them to the form (from 1 to 70 , where 70 is a sign of a high level of this criterion for the development of the business environment).

C) The construction of indeces to a methodologically joint view for further integration. Since the set of indices selected by us for assessing the level of development of the business environment of the country is rather heterogeneous, it contains absolute and relative indicators expressed in natural and value units, as well as in percentage and units (analytical coefficients, specific gravity), to a methodologically joint view for further integration. For this purpose, we use the rating method already described in the previous paragraph of the algorithm.

D) Calculation of the integral index of the development of the business environment of the country. Calculation of the integral index for each of the indices is performed using the multidimensional simple average method: 


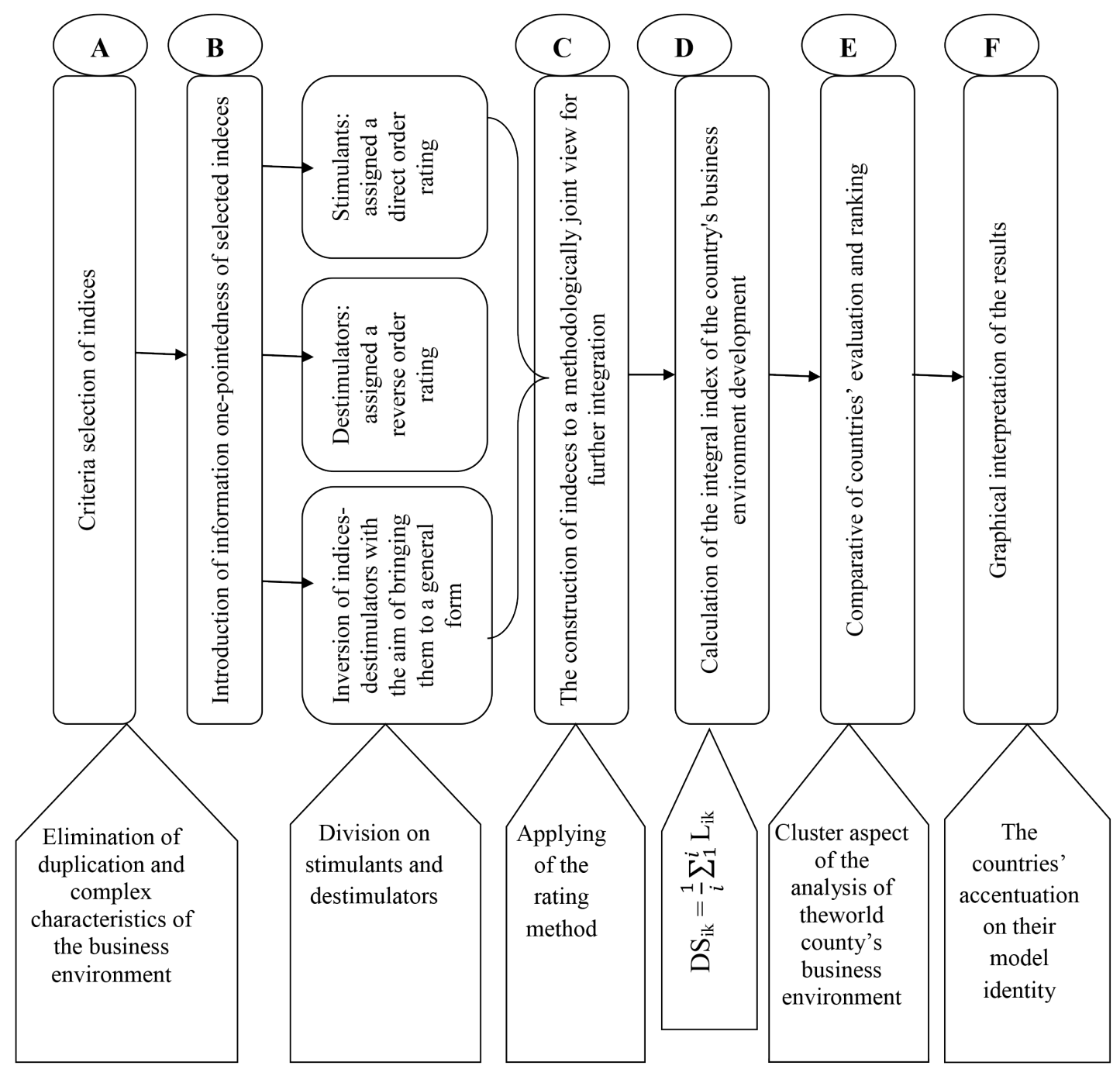

Figure 1. Algorithm of assessing level of development of the global business environment

Source: compiled by the author

$$
\mathrm{DS}_{\mathrm{ik}}=\frac{1}{i} \sum_{1}^{i} \mathrm{~L}_{\mathrm{ik}}
$$

where $\mathrm{DS}_{\mathrm{ik}}$ - integral index of business climate of the country;

$\mathrm{i}$ - number of selected indices (in this case 9);

$\mathrm{k}$ - a specific country for which the index is calculated (in this case from 1 to 70 )

$\mathrm{L}_{\mathrm{ik}}$ - indicator (ranking) $\mathrm{i}$ - index (in this case 1 to 9) for the k-th country.

The exact significance of the integral index has no economic interpretation, it is important only for place that belongs to each region on a single scale.

E) Comparative evaluation and ranking of countries in accordance with the value of the integrated index of business environment development (cluster aspect of the analysis of the business environment of the countries of the world). At this stage, we consider it expedient to use one of the types of cluster analysis. For this purpose, clustering of the level of development of the business environment is carried out on clusters (we offer 7 clusters for countries that demonstrate: the highest, high, medium, sufficient, low, the lowest, initial level of development). Moreover, within the framework of cluster analysis, we can not allow simple mathematical division of the interval boundaries of the integral index of the development of the country's business environment into identical parts. For each individual case, its step and its corresponding interval sections are calculated, which significantly improves the quality of cluster analysis.

F) Graphical interpretation of the results. It should be noted that all stages of the proposed methodology are carried out with accentuation not only on the countries, but also on their model identity (European, North American, Latin American, African, Far Eastern, Islamic, Indian, oceanic). Let us turn to the second task set by us (B): following the proposed methodology, we will analyze the level of development of the business 
environment of the countries of the world within the classification limits introduced by the author (Suray, 2016) with the aim of further clustering and graphical interpretation of the results obtained. We will only consider the final result tables, omitting a significant part of the intermediate calculations. As criterial selection of indices, it is assumed at the first stage, we have already substantiated, therefore we proceed to point $\ll B \gg$ of the proposed methodology.

The stage $\ll \mathrm{B} \gg$ involves the introduction of information onedirectionality of selected indices produced by differentiating their impact on the business environment of the country, both positive (stimulants) and negative (destimulators). In our case, stimulants are Country Brand Index, Democrqacy Index, Index of Economic Freedom, Human Development Index, Global City Competitiveness Index, Ease of Doing Business Index, Press Freedom Index; destimulators, respectively, Corruption Perception Index and Fragile Cointry Undex.

The results of the rating are reflected in Table 1.

The countries entering the North American model of business environment development remain the leader unchanged throughout the analyzed period. This model has lost the leading position only once, losing the leadership of the European model, takes the stable second place. The countries of the Indian and the Island models occupy invariably low positions throughout the entire study period, namely 7 and 8 places respectively. At the stage $\langle\mathrm{C} \gg$, the indices are reduced to a methodically joint view for further integration. For this purpose, we use the rating method already described in the previous paragraph of the algorithm. At the stage $\langle\mathrm{D} \gg$, the integral index of development of the business environment of the country is calculated.

In the framework of the stage $\ll \mathrm{E} \gg$, a comparative assessment and ranking of countries is carried out in accordance with the value of the integrated business environment development index. In our case, we have a viriable cluster analysis for 2017. To this end, we will organize groupings into 7 zones in increments of 8 , covering the following interval boundaries of the integral index of the development of the business environment of the country from 4.33 to 60.44 : Zone 1 to 12.33 ; Zone 2 from 12.34 to 20.34; Zone 3 from 20.35 to 28.35; Zone 4 from 28.36 to 36.36; Zone 5 from 36.37 to 44.37 ; Zone 6 from 44.38 to 52.38 ; Zone 7 more than 52.39.

Proceeding from the above mentioned, we proposed 7 clusters for countries that demonstrate: the highest, high, medium, sufficient, low, the lowest, initial levels of business environment development, which are reflected in Table 2:

Thus, the group of leaders is formed by countries that relate to different models of the business environment. The countries of the European model are Germany, Great Britain, Sweden, the Netherlands and Austria. North American model: Canada and the United States of America. Representative of the Far Eastern model is Japan, as well as Australia which belongs to the other models. The group of outsiders include countries that have a poor integrated index of business environment development, they are representatives of the African (Angola, Congo, Chad), Islamic (Syria, Somalia, Sudan) and Island (Polynesia) models.

\section{Method of analyzing the level of development of the business environment of the regions of Ukraine}

The active and rapid changes in the information support of world markets, the integration and globalization of national and regional markets, the transnationalization of production will require increasing and changes in the assessment of key processes. First of all it concerns the assessment

Table 1

Rating of business environment models according

to the Business Environment Development Index in 2013-2017

\begin{tabular}{|c|c|c|c|c|c|c|c|c|c|}
\hline \multicolumn{2}{|c|}{$\begin{array}{c}\text { The average } \\
\text { Business } \\
\text { Envi-ronment } \\
\text { De-velopment Index }\end{array}$} & \multirow{2}{*}{$\begin{array}{c}\begin{array}{c}\text { European } \\
\text { model }\end{array} \\
6,43\end{array}$} & \multirow{2}{*}{$\begin{array}{c}\text { North } \\
\text { American } \\
\text { model }\end{array}$} & \multirow{2}{*}{$\begin{array}{c}\begin{array}{c}\text { Latin Ameri- } \\
\text { can model }\end{array} \\
22,54\end{array}$} & \multirow{2}{*}{$\begin{array}{r}\begin{array}{r}\text { African } \\
\text { mod-el }\end{array} \\
24,33\end{array}$} & \multirow{2}{*}{$\begin{array}{c}\begin{array}{c}\text { Far Eastern } \\
\text { model }\end{array} \\
12,96\end{array}$} & \multirow{2}{*}{$\begin{array}{r}\begin{array}{r}\text { Islamic } \\
\text { model }\end{array} \\
24,15\end{array}$} & \multirow{2}{*}{$\begin{array}{r}\begin{array}{r}\text { Indian } \\
\text { model }\end{array} \\
25,84\end{array}$} & \multirow{2}{*}{\begin{tabular}{|c|}
$\begin{array}{c}\text { Island model } \\
\text { (Oceanian } \\
\text { countries) }\end{array}$ \\
31,72 \\
\end{tabular}} \\
\hline 2013 & Value & & & & & & & & \\
\hline 2013 & Rating & 2 & 1 & 4 & 6 & 3 & 5 & 7 & 8 \\
\hline \multirow{2}{*}{2014} & Value & 8,04 & 5,39 & 22,8 & 22,74 & 13,96 & 24,48 & 25,84 & 29,58 \\
\hline & Rating & 2 & 1 & 5 & 4 & 3 & 6 & 7 & 8 \\
\hline \multirow{2}{*}{2015} & Value & 8,04 & 5,39 & 22,8 & 22,74 & 13,96 & 24,49 & 25,84 & 29,58 \\
\hline & Rating & 1 & 2 & 5 & 4 & 3 & 6 & 7 & 8 \\
\hline \multirow{2}{*}{2016} & Value & 6,45 & 5,67 & 21,87 & 22 & 13,47 & 25,29 & 26,2 & 32,33 \\
\hline & Rating & 2 & 1 & 4 & 5 & 3 & 6 & 7 & 8 \\
\hline \multirow{2}{*}{2017} & Value & 6,69 & 4,72 & 22,13 & 24,22 & 12,73 & 26,13 & 27,04 & 32,33 \\
\hline & Rating & 2 & 1 & 4 & 5 & 3 & 6 & 7 & 8 \\
\hline
\end{tabular}

Source: calculated by the author 
Table 2

Groupings of countries into clusters according to the level of business envi-ronment development in 2017

\begin{tabular}{|c|c|c|c|c|}
\hline Business environment model & Country & The integral index at 2015 & Rating & $\begin{array}{c}\text { The level of business } \\
\text { environment } \\
\text { development }\end{array}$ \\
\hline North American model & Canada & 4,33 & 1 & \multirow{9}{*}{ The highest } \\
\hline European model & Germany & 4,89 & 2 & \\
\hline European model & The United Kingdom & 5,44 & 3 & \\
\hline European model & Sweden & 5,44 & 4 & \\
\hline Other models & Australia & 6,00 & 5 & \\
\hline North American model & The USA & 6,22 & 6 & \\
\hline European model & The Netherlands & 6,33 & 7 & \\
\hline European model & Austria & 10,11 & 8 & \\
\hline Far Eastern model & Japan & 10,33 & 9 & \\
\hline Far Eastern model & South Korea & 12,56 & 10 & \multirow{8}{*}{ High } \\
\hline European model & France & 12,67 & 11 & \\
\hline Far Eastern model & Singapore & 13,67 & 12 & \\
\hline Latin American model & Chile & 14,56 & 13 & \\
\hline European model & Italy & 15,22 & 14 & \\
\hline Far Eastern model & Taiwan & 16,67 & 15 & \\
\hline European model & Poland & 17,78 & 16 & \\
\hline European model & Spain & 20,22 & 17 & \\
\hline Latin American model & Uruguay & 21,56 & 18 & \multirow{6}{*}{ Average } \\
\hline Islamic model & United Arab Emi-rates & 21,67 & 19 & \\
\hline Islamic model & Qatar & 24,67 & 20 & \\
\hline Latin American model & Peru & 25,56 & 21 & \\
\hline North American model & Mexico & 26,78 & 22 & \\
\hline African model & South Africa & 27,89 & 23 & \\
\hline African model & Botswana & 28,44 & 24 & \multirow{14}{*}{ Sufficient } \\
\hline Indian model & Thailand & 28,67 & 25 & \\
\hline Latin American model & Colombia & 29,00 & 26 & \\
\hline European model & Turkey & 29,22 & 27 & \\
\hline Far Eastern model & Mongolia & 30,33 & 28 & \\
\hline Latin American model & Brazil & 30,44 & 29 & \\
\hline Islamic model & Saudi Arabia & 30,44 & 30 & \\
\hline Far Eastern model & China & 31,22 & 31 & \\
\hline Latin American model & Argentina & 32,78 & 32 & \\
\hline Indian model & India & 33,56 & 33 & \\
\hline Indian model & Indonesia & 34,22 & 34 & \\
\hline Islamic model & Oman & 34,89 & 35 & \\
\hline Indian model & Philippines & 35,11 & 36 & \\
\hline Other models & Russia & 36,22 & 37 & \\
\hline Latin American model & Paraguay & 36,67 & 38 & \multirow{10}{*}{ Low } \\
\hline Other models & Kazakhstan & 37,11 & 39 & \\
\hline European model & Ukraine & 37,33 & 40 & \\
\hline Latin American model & Cuba & 38,67 & 41 & \\
\hline Latin American model & Ecuador & 39,11 & 42 & \\
\hline Indian model & Sri Lanka & 39,78 & 43 & \\
\hline Indian model & Vietnam & 41,00 & 44 & \\
\hline Latin American model & Bolivia & 42,22 & 45 & \\
\hline Islamic model & Algeria & 42,22 & 46 & \\
\hline Islamic model & Egypt & 43,00 & 47 & \\
\hline Islamic model & Iran & 44,56 & 48 & \multirow{6}{*}{ The least } \\
\hline Islamic model & Kenya & 44,67 & 49 & \\
\hline Indian model & Nepal & 46,22 & 50 & \\
\hline Islamic model & Libya & 47,56 & 51 & \\
\hline Indian model & Pakistan & 47,67 & 52 & \\
\hline African model & Ethiopia & 47,78 & 53 & \\
\hline
\end{tabular}




\begin{tabular}{|c|c|c|c|c|}
\hline Business environment model & Country & The integral index at 2015 & Rating & $\begin{array}{c}\text { The level of business } \\
\text { environment } \\
\text { development }\end{array}$ \\
\hline Island model & The Hawaii islands & 47,89 & 54 & \multirow{10}{*}{ The least } \\
\hline Indian model & Myanmar & 48,11 & 55 & \\
\hline Island model & Antilles & 48,44 & 56 & \\
\hline African model & Mali & 48,56 & 57 & \\
\hline Latin American model & Venezuela & 48,67 & 58 & \\
\hline Island model & Easter Island & 50,22 & 59 & \\
\hline African model & Niger & 50,67 & 60 & \\
\hline Islamic model & Iraq & 50,89 & 61 & \\
\hline Indian model & Afghanistan & 52,00 & 62 & \\
\hline Islamic model & Yemen & 52,11 & 63 & \\
\hline Island model & Polynesia & 53,00 & 64 & \multirow{7}{*}{ Initial } \\
\hline Islamic model & Syria & 54,11 & 65 & \\
\hline African model & Angola & 54,44 & 66 & \\
\hline Islamic model & Somalia & 55,00 & 67 & \\
\hline Islamic model & Sudan & 55,56 & 68 & \\
\hline African model & Congo & 59,67 & 69 & \\
\hline African model & Chad & 60,44 & 70 & \\
\hline
\end{tabular}

Source: calculated by the author

of the business environment. At the global level, analytical organizations monitor a significant number of indicators that somehow reflect the characteristics of the functioning and development of the business environment. In the regional context, for Ukraine the first attempt to make a corresponding assessment was made just in 2015. This happened within the framework of the USAID Leadership in Economic Management Program, which included the development of a special national tool, the Annual Assessment of the Business Climate (Annual assessment, 2017).

The business environment is volatile and requires monitoring, assessing states and constituents from the government agencies in order to adjust regional development policies and directly regional management bodies. Attracting a reasonable, collective assessment of private analytical sources, consulting provides the latest quality and increased efficiency in the implementation of management functions. This necessitates the development of a methodology for analyzing the business environment of Ukraine, which was better adapted specifically to its economic, social and cultural characteristics, based on official information provided by domestic organizations of the public and private sectors of the economy. Such an assessment is impossible without a systematic set of data reflecting the state of the phenomenon being studied and will become the starting point of the analysis. So, based on the data of domestic state and non-state organizations, we propose a range of indicators reflecting the peculiarities of the business environment in the context of Ukrainian regions and systematized into seven subsystems (economic, political, legal, social, institutional, informational, environmental) (Suray, 2017). The proposed study will be the basis for developing a methodology for analyzing the business environment of a region as a multicomponent phenomenon (Suray, 2017).

So, the analysis of the business environment of the regions can be made on the basis of official information of the State Statistics Service of Ukraine with a regional transcript and relevant additions. Each group of indicators characterizes a specific subsystem of the business environment. Official information of the State Statistics Service of Ukraine allows a quantitative assessment of the economic, social, political, legal, institutional, informational and environmental subsystems, as a comprehensive description of the business environment of the region. The dynamics of the statistical data presented on most of the indicators for the studied years $(2007,2012,2017)$ makes an assessment of the dynamic level of the business environment in each region and makes it possible to qualify the static nature or variability of the meso-environment. The goal was to cover the maximum number of criteria, it is a systemic form relative to the business environment, therefore, quantitative and qualitative indicators (which will be discussed below) were taken into account, which today remain unformalized.

A study of the informativeness of the statistical base for evaluating the components of the business environment indicated that it is advisable to take into account 40 statistical indicators reflecting various aspects of the business and cover the seven main subsystems of the business environment. The indicators are defined as the basis of the proposed methodology for assessing the level of development of the business environment. The assessment methodology consists of eight stages, filled with appropriate actions and analytical procedures, 
involving the use of the following methods: regressioncorrelation; index; cluster; graphic; rating; expert assessments (Pankova, 2019).

The sequence of the evaluation procedure is as follows:

1. The criterial selection of indicators, which in the complex, with their component composition, do not duplicate each other, but complement, in this way reflect and provide a certain quantitative characteristic of each of the subsystems of such a multivariate phenomenon as a business environment. Forty indicators of seven subsystems of the business environment, providing a complex characteristic of the phenomenon, are proposed.

2. The construction of indicators to methodically cooperative activities. Since the set of indicators selected to assess the level of development of a country's business environment is heterogeneous, it presents absolute and relative indicators expressed in different units of measurement, which requires their reduction to a methodically joint form for further integration. For this purpose, the rating method was used.

3. Provision of an informative one-wayness of selected indicators. We classify all indicators that reflect the different facets of the development and functioning of the business environment of the country's regions into two groups: stimulants and disincentives.

Thus, while developing a methodology for the information-related conditions of the regions of Ukraine we include into the selection all regions without exception that play the role of components in the index method. This will allow to achieve high accuracy of calculations, and consequently, high reliability of conclusions. To this end, we propose to use the technique of the scope of variation (Jyoti, 1992).

3.1. Regarding the indicators-stimulators we apply the formula (2) (Jyoti, 1992).

$$
D_{i j}=\frac{\text { Aij }- \text { Ajmin }}{\text { Ajmax }- \text { Ajmin }} \text {, }
$$

3.2. For indicators-destimulators we apply the formula (3) (Jyoti, 1992).

$$
D_{i j}=\frac{\text { Ajmax }- \text { Aij }}{\text { Ajmax }- \text { Ajmin }},
$$

Where $D_{i j}$ - standardized value of subaggregates of $j$ in i-region;

Aij - the measured value of subaggregates of $j$ for the i-region;

$A_{i}^{\max }, A_{j}^{\min }-$ maximum and minimum values $j$ of subaggregates.

4. Calculation of the integral subscript of the development of seven subsystems of the business environment in a regional context. The calculation of integral subscript, based on the indicators that form the statistical base of the seven subsystems, should be carried out separately for each subsystem and in a regional context. The procedure is carried out using the method of multidimensional simple

$$
S_{\mathrm{ig}}=\mathrm{D}_{\mathrm{ikj}}{ }^{\mathrm{H}} \text {, }
$$

where Sig is a overall index of the $\mathrm{g}$ subsystems of subaggregates of business environment in the $\mathrm{i}-$ region, $\mathrm{g}=\overline{1,7}$ and $\mathrm{i}=\overline{1,27}$ - pIDEBE, pIDSBE, pIDPBE, pIDLBE, pIDIBE, pIDInfBE, pIDEBE;

pIDEBE - partial index of development economic business environment; pIDSBE - socialhttps://www. multitran.ru/c/m.exe?t=1929543_1_2\&s1=\%EF\%EE \%E4\%F1\%E8\%F1\%F2\%E5\%EC\%E0; pIDPBE - political; pIDLBE - legal; pIDIBE - institutional; pIDInf$\mathrm{BE}$ - informational; pIDEBE - ecological business environment;

$\mathrm{D}_{\mathrm{ikj}}^{\mathrm{H}}$ - standardized value $\mathrm{j}$-subscript g-subsystem in i-region; $g$ - number of subsystem of indicators, $g=\overline{1,7}$;

$\mathrm{m}_{\mathrm{k}}$ - number of indicators g-subsystem;

$j$ - the $j$-indicator of the g-subsystem.

The obtained intermediate values in the context of regions will be formed into seven groups-subsystems with the aim of further calculating indicators of the level of development of the business environment for each regional subsystem.

5. The determination of the weights for the seven subsystems of the business environment are determined as a result of two successive stages:

5.1. Using the method of expert assessments (respondents are representatives of the top management of business structures (small, medium and large businesses) and representatives of state and regional organizations that have regulatory impact on the business environment of the region).

5.2. Using the tools of a multi-component prototype of the business environment proposed in the previous section of the study to obtain the weight of each of the subsystems.

The total sum of the specific gravity of each subsystem is denoted by $\mathrm{CH}$, for this indicator the fair equation (5) (Jyoti, 1992):

$$
\mathrm{CH}=\sum_{g=1}^{i g} \mathrm{CHg}=1 \text {, }
$$

where $\mathrm{CHg}$ - weighing coefficient g- business environment subsystems of the region, and $g=\overline{1,7}$ and $\mathrm{g}=\overline{1,27}$.

6. The calculation of the integral index of the business environment in the regional context. The integral index of the level of development of the business environment of the i-th region (IILDERi) was obtained by using the method of calculating the richly weighted average (6) (Jyoti, 1992):

$$
\text { IILDERi }=\mathrm{CHgS}_{\mathrm{ig}}(6)
$$

where $\mathrm{CHg}$ is the weighted coefficient of the $\mathrm{g}$-subsystem of the business environment of the i-region, $\mathrm{g}=\overline{1,7}$ and $\mathrm{g}=\overline{1,27}$;

$S_{\mathrm{ig}}$ - integral subaggregates of the g-subsystem of the business environment of the i-region, $g=\overline{1,7}$ and $\mathrm{g}=\overline{1,27}$; 
7. Comparative assessment, ranking of regions with subsequent clustering according to the value of the integral index of the development of the business environment. At this stage, we consider it appropriate to use the mathematical procedure of cluster analysis. Moreover, within the cluster analysis we will not allow a simple mathematical division into intervals of the integral business environment development index of the country into equal parts. For each individual case, we calculate our step and the corresponding interval segments, which significantly improves the quality of cluster analysis. The Sturges' rule is a scientifically recognized method for determining the optimal number of ranges (Sturges, 1926). Its formulaic interpretation is (7):

$$
\Delta=\mathrm{V} /(1+3,322 \cdot \lg \mathrm{N}) \text {, }
$$

where $\mathrm{N}$ - number of elements, $\mathrm{N}=27$;

$\mathrm{V}$ - range of values of the integral index of the development of the business environment.

8. Graphic interpretation of the results. Graphic interpretation will allow to visualize the data obtained, will provide greater visibility of the research results. Built in the form of a map of Ukraine with the allocation of geographical clusters, differentiated by the level of development of the business environment, can be used to make decisions on regulatory policies at both the state and regional levels. It is advisable to introduce this technology in the framework of the implementation of the «State Strategy for Regional Development for the period up to $2020 \gg$. The proposed approach to assessing the level of development of the business environment of the regions of Ukraine is an effective mechanism: the formalization of the business environment of the regions; creating conditions for conducting a regional comparison of development processes (and not only in the internal evaluation system, comparisons with European regions are possible); accelerate investor decision making; justification of the results obtained, the development and implementation of policies at both regional and state levels, corresponding to the specific characteristics of each territory or region.

\section{Problems of asymmetry of business environment development in the regions of Ukraine: approbation of the methodology}

The practical value of any research activity is in disclosing its practical value, a description of how the results obtained during the study can be applied. So, the following research tasks are recommended to consider adaptation and testing of the proposed methodology for analyzing the level of development of the business environment of the regions of Ukraine to domestic conditions. We will consider only the final result tables, omitting a significant part of the intermediate calculations.

1. Criterial selection of indicators. The advantage of the proposed method is that the researcher, adhering to the main stages of its algorithm, can work with a flexible set of input data. Let us return to the main subsystems that form a comprehensive view of the business environment and quantitative data (indicators of the State Statistics Service of Ukraine), which in the framework of the study were selected from the official statistical database to reflect the state of these subsystems. All empirical data are distributed respectively on the seven subsystems that form the business environment and consist of forty statistical indicators.

We suggest evaluating the economic subsystem of the business environment by the following groups of indicators:

1.1. As constituent indicators for assessing of the commercial component of the economic subsystem of the business environment of the region used: the Gross Regional Product; Gross Regional Product per capita; the number of economically active population; fixed investment; profitability of operating activity.

1.2. The financial subsystem can be evaluated using the following indicators: region's share of the country's tax debt in the total amount; staff costs of the subjects of economic activity of the region; number of financial institutions;arrearage in salaries; financial results of activity of subjects of economic activity of the region before taxation.

1.3. The communication subsystem, its state and dynamics can be estimated using the following indicators: mobile (mobile) communication; transported (sent) goods; passed (sent) passengers revenues from postal activity.

1.4. As part of the evaluation of the technologically innovative business environment subsystem, we use statistical data: the number of organizations that are engaged in research and development; number of scientific personnel; volume of performed scientific and technical works; studying expenses; the share of subjects of the economic activity of the region, which have introduced innovations.

We characterize the social subsystem using indicators: population size, consumer price index, migration indicators, unemployment rate, population incomes, natural movement of the population. The political subsystem is estimated using indicators: the number of political organizations; the number of persons brought to administrative responsibility. The legal subsystem demonstrates the state of compliance / violation of the law and its impact on the activities of business entities: non-payment of salaries, scholarships, pensions or other statutory payments; misappropriation, embezzlement or seizure of property through abuse of official position; legalization (laundering) of proceeds from crime; abuse of power or official position; corrupt practices. We will characterize the institutional subsystem based on the following indicators: the number of business entities in the region, the number of employed workers in business entities, the volume of products sold (goods, 
services). The informative subsystem is estimated by the indicators: income from fixed telephone communication, broadcasting network and radio communication, Internet services. The main indicators for assessing the environmental subsystem are: emissions of pollutants into the atmosphere, the amount of neutralized substances polluting the atmosphere.

2. Summarizing the indicators to a methodically joint form. At this stage, the construction of empirical data (forty indicators in the context of subsystems for each of the regions of Ukraine and taking into account the time trend for the period 2007, 2012, 2017) to a systematically joint form.

Due to the fact that, since 2014, the Official Statistical Statement do not take into account the data of the Autonomous Republic of Crimea and the city of Sevastopol, and to achieve uniformity and comparability of data, it was decided to unify the entire time trend with the exception of data from the specified regions from 2007 and 2012. That is why, these regions are excluded from all tables, where the results of the study will be presented. The main tool for analysis and evaluation is the rating method.

3. Ensuring the one-wayness of the information on selected indicators. As it was already noted, the methodology proposed for analyzing the business environment of a particular country (Ukraine in our case) is more accurate due to the application of the method of theoretical range of variation.

4. Calculation of the subscript of development index of the seven subsystems of the business environment in a regional context: pIDEBE, pIDSBE, pIDPBE, pIDLBE, pIDIBE, pIDInfBE, pIDEBE. It is important that the analysis is carried out necessarily in the context of the seven subsystems indicated by us, since each of them has its own individual weight in the formation of the final indicator, will provide an idea of the state of development of the region's business environment in time sections: 2007, 2012 and 2017. At this stage the mathematical multidimensional simple average method was used.

5. The determination of intermediate coefficients for the proposed seven subsystems of the business environment is carried out and based on the results of expert conclusions of scientists, top management of business structures that provided the weight of each of the subsystems (the total weight is 1.0 ): the economic subsystem is 0.33 ; social subsystem is 0.25 ; political subsystem is 0.08; legal subsystem is 0.14 ; institutional subsystem is 0.08 ; information subsystem is 0.08 ; environmental subsystem is 0.04 .

The most important factor in the formation and development of the business environment, according to the results of the fifth stage of evaluation, are economic and social systems. The smallest role in the formation and development of the business environment belongs to the ecological subsystem. These results indicate a significant role for the economic processes taking place in the business environment, insufficient development of social management in Ukraine, low ecological awareness and a culture of doing business. In this way, we obtained the $\mathrm{CHg}$ indicators, i.e. the weight factors of the g- th subsystem of the business environment, which are necessary for calculating the integral index of the business environment in a regional context.

6. Calculation of the integral index of the development of the business environment in a regional context. The previous paragraph provides a general formula for calculating the integral index of business environment development. By transferring this equation to the indicators of each of the subsystems of the business environment, calculated in p.1-5 of the method, we obtain the equation (8):

$$
\begin{aligned}
& \text { IILDERi }=\mathrm{CH}_{1}{ }^{*} \mathrm{pIDEBE}+\mathrm{CH}_{2}{ }^{*} \mathrm{pIDSBE}+ \\
& +\mathrm{CH}_{3}{ }^{*} \mathrm{pIDPBE}+\mathrm{CH}_{4}{ }^{*} \mathrm{pIDLBE}+\mathrm{CH}_{5}{ }^{*} \mathrm{pIDIBE}+ \\
& +\mathrm{CH}_{6}{ }^{*} \mathrm{pIDInfBE}+\mathrm{CH}_{7}{ }^{*} \mathrm{pIDEBE}
\end{aligned}
$$$$
\text { where } \mathrm{i}-\text { the region, } \mathrm{i}=\overline{1,27} \text {. }
$$

Also, by entering into the equation the specific values of the weights of the seven subsystems of the business environment, we obtain equation (9):

$$
\begin{aligned}
& \text { IILDERi }=0,33^{*} \mathrm{pIDEBE}+0,25^{*} \mathrm{pIDSBE}+ \\
& +0,08^{*} \mathrm{pIDPBE}+0,14^{*} \mathrm{pIDLBE}+0,08^{*} \mathrm{pIDIBE}+ \\
& +0,08^{*} \mathrm{pIDInfBE}+0,05^{*} \mathrm{pIDEBE}
\end{aligned}
$$

The resulting equation was used to determine the level of the integral index of the development of the business environment of twenty-seven territorial units of Ukraine for the period 2007, 2012, 2017.

In the framework of the proposed methodology, the integral indicator of the level of the region's business environment varies from 0 to 1.0. The closer the indicator is to 1.0, the higher the level of development of the business environment. The result of the calculation of the integral index of the level of development of the business environment of the region is the hierarchically located regions of Ukraine, which criterion for differentiating is taken as the value of the integral indicator. The specific value of the integral index (or indices characterizing separate subsystems of the business environment) does not have an economic interpretation, but only the place that belongs to each region on a single scale is important.

So, the author has calculated the integral indices of the economic, social, political, legal, institutional, informational and ecological subsystems of the business environment of Ukraine. Their results allowed us to obtain an integral index of the business environment of the regions of Ukraine (Table 3).

7. Comparative assessment, ranking of regions with subsequent clustering according to the value of the integral index of the development of the business environment. The determination of the optimal number of ranges was carried out in accordance with the Sturges' formula. The calculation is carried out for a sample of 
Vol. 5, No. 5, 2019

Table 3

Integral Index of Development of the Business Environment of Ukraine's Regions

in 2007, 2012, 2017, calculated according to the author's method

\begin{tabular}{|c|c|c|c|}
\hline \multicolumn{4}{|c|}{ The index of development of the business environment of the region } \\
\hline \multirow{2}{*}{ Region } & \multicolumn{3}{|c|}{ The index of development of the business environment of the region } \\
\hline & 2007 & 2012 & 2017 \\
\hline Vinnytsia & 0.391 & 0,387 & 0.394 \\
\hline Volyn & 0.397 & 0.392 & 0.392 \\
\hline Dnipropetrovsk (Dnipro) & 0,436 & 0.431 & 0.402 \\
\hline Donetsk & 0.414 & 0,387 & 0.254 \\
\hline Zhytomyr & 0,383 & 0.347 & 0.367 \\
\hline Zakarpattia & 0.382 & 0.36 & 0.369 \\
\hline Zaporizhzhia & 0.423 & 0,353 & 0.374 \\
\hline Ivano-Frankivsk & 0,371 & 0.394 & 0.391 \\
\hline Kyiv & 0.452 & 0.437 & 0.412 \\
\hline Kirovograd (Kropyvnytskyi) & 0.384 & 0.362 & 0,383 \\
\hline Luhansk & 0.297 & 0.314 & 0.314 \\
\hline Lviv & 0,427 & 0,371 & 0.417 \\
\hline Mykolayiv & 0.392 & 0.368 & 0,376 \\
\hline Odesa & 0.401 & 0.402 & 0.355 \\
\hline Poltava & 0.354 & 0,377 & 0,378 \\
\hline Rivne & 0.364 & 0.343 & 0.350 \\
\hline Sumy & 0.368 & 0.362 & 0.362 \\
\hline Ternopil & 0.404 & 0.381 & 0.372 \\
\hline Kharkiv & 0.432 & 0.439 & 0.405 \\
\hline Kherson & 0.395 & 0.365 & 0.367 \\
\hline Khmelnytskyi & 0.385 & 0,376 & 0,388 \\
\hline Cherkasy & 0.373 & 0.384 & 0.381 \\
\hline Chernivtsi & 0.384 & 0.385 & 0.396 \\
\hline Chernihiv & 0,389 & 0,356 & 0.333 \\
\hline The city of Kyiv & 0.754 & 0.717 & 0.736 \\
\hline
\end{tabular}

Source: calculated by the author

the business environment development indices of the regions separately for each year of 2007, 2012, 2017.

The range of variation of the regional business environment development index in 2017 will be equal to (10) (Sturges, 1926):

$\mathrm{V}_{2017}=\mathrm{V}_{\max 2017}-\mathrm{V}_{\min 2017}=0,73-0,25=0,48$.

The range of variation of the regional business environment development index in 2012 will be equal to $(11)$ :

$\mathrm{V}_{2012}=\mathrm{V}_{\max 2012}-\mathrm{V}_{\max 2012}=0,71-0,31=0,40$.

The range of variation of the regional business environment development index in 2007 Will be equal to $(12)$ :

$$
\mathrm{V}_{2007}=\mathrm{V}_{\max 2007}-\mathrm{V}_{\max 2007}=0,75-0,29=0,46 \text {. }
$$

To calculate the ranges of the index of development of the business environment of the regions in 2017, there is the equation $(13,14)$ :

$$
\begin{aligned}
& \Delta_{2017}=\mathrm{V}_{2017} / 1+3,322 \cdot \operatorname{lgN} ; \\
& \Delta_{2017}=0,48 / 1+3,322 \cdot \lg 27=0,024 .
\end{aligned}
$$

To calculate the ranges of the index of development of the business environment of the regions in 2017, there is the equation $(15,16)$ :

$$
\begin{aligned}
& \Delta_{2012}=\mathrm{V}_{2012} / 1+3,322 \cdot \operatorname{lgN} \\
& \Delta_{2012}=0,4 / 1+3,322 \cdot \lg 27=0,018 .
\end{aligned}
$$

To calculate the ranges of the index of development of the business environment of the regions in 2017, there is the equation $(17,18)$ :

$$
\begin{aligned}
& \Delta_{2007}=\mathrm{V}_{2007} / 1+3,322 \cdot \lg \mathrm{N} ; \\
& \Delta_{2012}=0,46 / 1+3,322 \cdot \lg 27=0,021 .
\end{aligned}
$$

The resulting ranges for the three time frames when rounding up to hundredths are reduced to step 0.020 . So, for $2007,2012,2017$, the range values are the same and make up: $\Delta_{-}(2007 ; 2012 ; 2017)=0.020$.

We will accomplish groupings with a step of 0.020 , into clusters according to the principle of differentiation according to the level of development of the region's business environment. It covers the interval limits of the investigated time range of the integral coefficient of development of the business environment from 0.730 to 0.250 . We received 5 clusters for regions, demonstrating respectively: high, moderate, medium, low, the lowest level of development. The names of clusters proposed by the author do not bear a separate semantic load, but they focus attention on the belonging of a certain region 
to a group with a similar level of development of the business environment among the general sample:

cluster 1 - more than 0.410 - high development of the business environment;

cluster 2 - 0.390-0.409 - moderate development of the business environment;

cluster 3 -0.370-0.389 - average development of the business environment;

cluster $4-0,350-0,369$ - low development of the business environment;

cluster 5 - less than 0.349 - the lowest development of the business environment.

The results of our grouping show that in 2017 Lviv, Kyiv region and the city of Kyiv became a cluster of high development. The cluster of moderate development included Kharkiv, Dnipropetrovsk, Chernivtsi, Vinnytsia, Volyn and Ivano-Frankivsk regions. The most common is the cluster of medium development of the business environment covering 7 oblasts: Khmelnytskyi, Kirovograd, Cherkasy, Poltava, Mykolayiv, Zaporizhzhia and Ternopil regions. The cluster of low development of the business environment includes Zakarpattia,
Zhytomyr, Kherson, Sumy, Odesa and Rivne regions. And the least common was the cluster of the lowest development of the business environment, which included the regions, where the integral index of the development of the business environment was below 0.349, namely: Donetsk, Luhansk and Chernihiv oblasts. The index of development the business environment of the regions of Ukraine, calculated by us, proves the extremely expressed polarization and unevenness of the processes of development of territories. Among the sam-pling frame, which included the regions with the highest level of development, the range of the integral index is so significant that, because of this, indicators of territories was not included in the cluster of leaders which become expressionless.

8. Graphical interpretation of the results obtained. The visualization of the results obtained in the previous stages of the calculation of the integral index and subsequent differentiation into clusters according the level of development (Figure 2) is the process of constructing a graphical data icon. We will give results for 2017 in the form of a map of Ukraine with a color gradation of

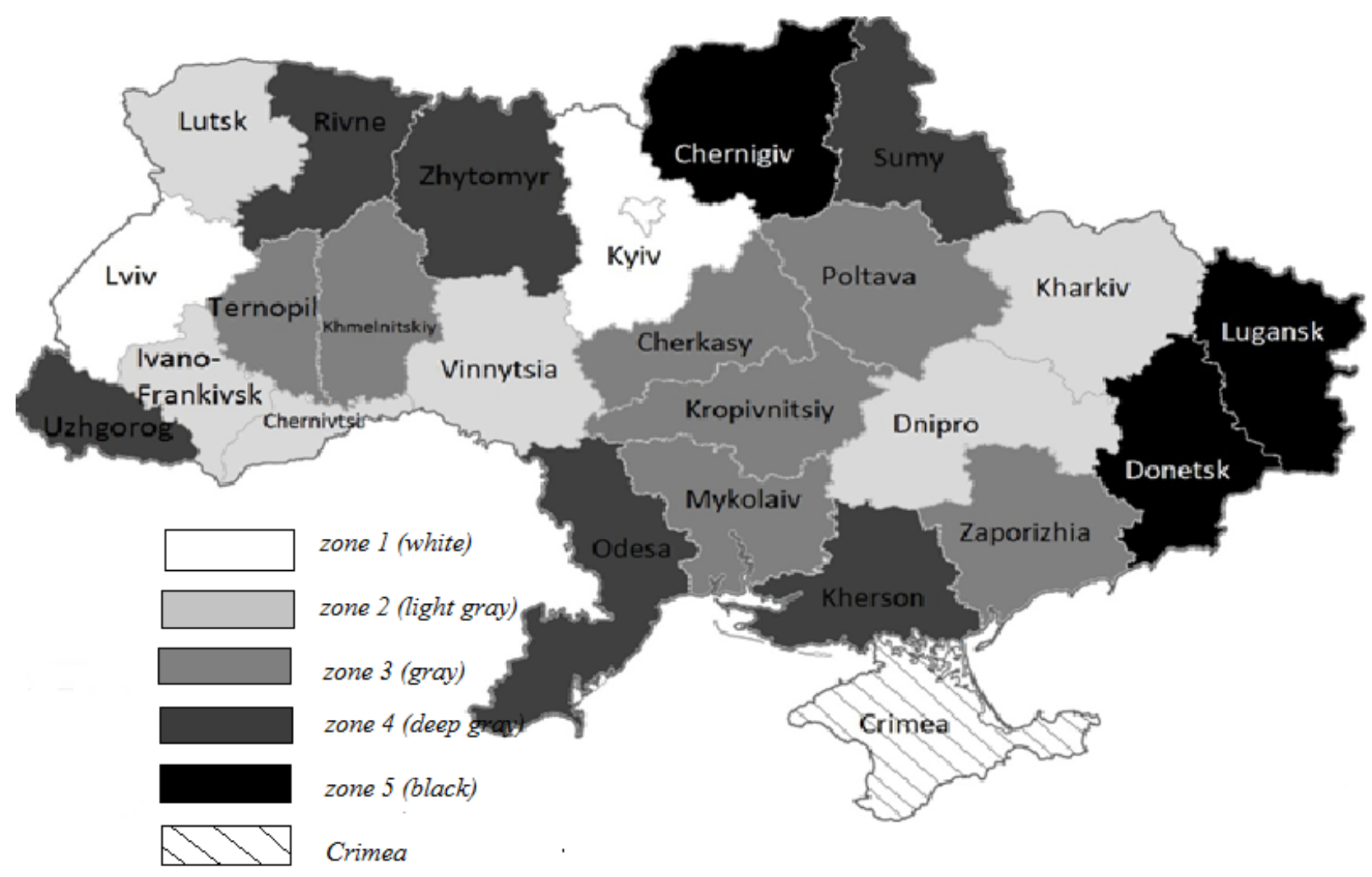

Legend:

zone 1 (white)- high development cluster;

zone 2 (light gray)- cluster of moderate development;

zone 3 (gray)- medium development cluster;

zone 4 (deep gray)- low development cluster;

zone 5 (black)-cluster of the lowest development of the business environment

zone 6 (stripped)-Crimea

Figure 2. Zoning of the regions of Ukraine according to the index of development of the business environment 2017 year

Source: compiled by the author 
clusters of regions according to the level of development of the business environment, offered at the preliminary stage of research from white to black color.

Demonstration of the received parameters of the level of development of the business environment in the form of development zones on the map of Ukraine during 2007, 2012, 2017 gives an opportunity to see trends in the development of regions and their mutual decomposition. Thus, Kyiv(city), Kyiv and Lviv regions remain absolute and unchanged leaders in the parameters of the business environment. In 2012, the Dnipropetrovsk region was among the leaders, and in 2007 the Kharkiv, Zaporizhzhia and Donetsk regions also included in the high-developed cluster.

According to the results of 2007, with a small margin from the leaders, Ternopil, Odesa, Dnipropetrovsk, Kherson, Mykolayiv and Vinnytsia regions were located in the zone of moderate development of the business environment. However, in 2012 the situation reversed and this group included only Odesa, Ivano-Frankivsk and Volyn regions. In 2017, the cluster expanded again and began to include Kharkiv, Dnipropetrovsk, Chernivtsi, Vinnytsia and Ivano-Frankivsk regions.

The cluster of low development of the business environment includes the regions with an index of development of the business environment within the range of $0.350-0.369$. In 2007 , such areas were Sumy, Rivne and Poltava regions. In 2012, the number of participants expanded significantly; Mykolayiv, Zakarpattia, Kherson, Sumy, Kirovograd, Chernihiv and Zaporizhzhia regions were added to the cluster. In 2017 , the low zone was formed by Zakarpattia, Zhytomyr, Kherson, Sumy, Odesa and Rivne regions. The cluster of the lowest development of the business environment includes the most depressed regions of Ukraine. In 2007 , it was only the Luhansk region, which, by the way, remained in this zone throughout the investigated period. In 2012 to the list were added Zhytomyr and Rivne regions, and in 2017 the enumeration was added by Chernihiv and Donetsk regions.
Thus, graphical interpretation, which is a tool for visualizing quantitative characteristics, provides greater visibility of the research results. The obtained zoning maps of the regions of Ukraine is a graphical interpretation of the comparative assessment and clustering of regions according to the level of development of the business environment. As a result, we received a formative evaluation of the business environment of the regions in a cluster perspective, together with the identification of the zones of greatest conflict.

\section{Conclusions}

Thus, we can summarize that in our hands there is an effective tool for con-ducting a comprehensive assessment of the level of development of the business environment both at the global and at the regional level. First of all, these are empirical data: indeces described by us, and based on the results of careful selection, we can create as complete a picture of the phenomenon as we can. Secondly, a six-step method for processing and interpreting the results obtained using the index, cluster, graphical, and rating methods was proposed. The results of the assessment will create conditions for regional and global comparison, will justify the results obtained, develop and implement a policy of both regional and state level, corresponding to the specific characteristics of each country, territory or region. We have formulated the evaluation parameters of the development of the business environment of the regions of Ukraine. It allowed to develop a methodological approach to diagnose the business environment of a region, grounded in the use of interconnected and complementary methods of its assessment based on official statistical information; expert estimation based on the ideas, thoughts and conclusions of scientists and top management of business structures; that allows to provide a relevant assessment, determine the direction of further development and identify opportunities for adequate support of the business environment of the region.

\section{References:}

Annual assessment of the business climate in 2017 (2017). Retrieved from: https://www.ukrinform.ua (accessed 09 September 2019).

Chukhno, A. (2008). Institutional architecture and institutional dynamics of development. Ukraine economy, vol. 7, pp. 137-143.

Finigina, O. V., \& Pankova, L. I. (2018). Key interests and principles of using the potential of cluster policy. Scientific development and achievement. London, vol. 1, pp. 264-278.

Hajek, F. A. (1992). Pernicious self-confidence. Errors of Socialism. Moscow:: «Novosti» Publishing House with the participation of Catallaxy, $304 \mathrm{p}$.

Jyoti, P. (1992). Statistical methods: an introductory text. New Age International, pp. 53-58.

Lewis, R. D. (2007). When cultures collide: Leading across cultures. Nicholas Brealey International, 593 p.

Mazur, I. I. (2012). Tinization of the economy of Ukraine in modern conditions. Bulletin of the Donetsk National University, vol. 2, pp. 52-57.

Ott Ursula, F. (2012). The Influence of Cultural Activity Types on Buyer-Seller Negotiations: A Game Theoretical Framework for Intercultural Negotiations. International Negotiation, vol. 16, pp. 427-450. 
Pankova, L. I. (2019). Economic interests of using the potential of the cluster policy in ensuring the sustainable development of the regions. Scientific journal "Bulletin of SUEEM" Series: Economics and Management, vol. 1(26), pp. $70-80$.

Shkarlet, S. M. (2014). Incorporation of the dominant information economy into the mechanism of ensuring sustainable development of the state. Socio-economic development of regions in the context of international integration, vol. 13, pp. 45-53.

Sturges, H. (1926). The choice of a class-interval. J. Amer. Statist. Assoc., no. 21, pp. 65-66.

Suray (Pavlovska), A. (2017). Methodological bases for monitoring the business environment in Ukraine: index of development level in a regional context. Intellect XXI, vol. 2, pp. 182-188.

Suray (Pavlovska), A. (2016). Bank of Pure Business Environment Models: Theoretical and Methodological Foundations. Collection of scientific works of Cherkasy State Technological University. Vol. 2. Series "Economic Sciences", pp. 86-95.

Voronchak, I. O. (2013). Regional aspects of the development of social responsibility of business in Ukraine: methodology and practice of evaluation. Economy. Management. Innovations. Retrieved from: http://nbuv.gov.ua/ UJRN/eui_2013_2_17 (accessed 17 November 2019). 